\title{
Six-Year Outcome of Opioid Maintenance Treatment in Heroin-Dependent Patients: Results from a Naturalistic Study in a Nationally Representative Sample
}

\author{
Michael Soyka ${ }^{a, b}$ Jens Strehle ${ }^{d}$ Jürgen Rehm ${ }^{d, e}$ Gerhard Bühringer ${ }^{c, d}$ \\ Hans-Ulrich Wittchen ${ }^{d}$

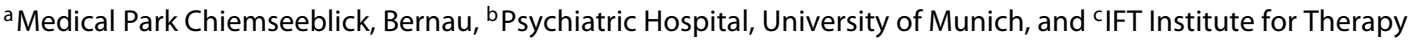 \\ Research, Munich, ${ }^{\mathrm{d} I n s t i t u t e}$ of Clinical Psychology and Psychotherapy, Technische Universität Dresden, Dresden,

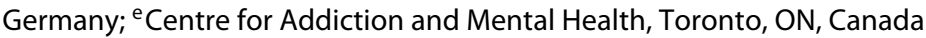

\author{
Keywords \\ Methadone · Buprenorphine - Opioids · Epidemiology · \\ Opioid dependence $\cdot$ Outcome
}

\begin{abstract}
Background: In many countries, the opioid agonists, buprenorphine and methadone, are licensed for maintenance treatment of opioid dependence. Many short-term studies have been performed, but little is known about long-term effects. Therefore, this study described over 6 years (1) mortality, retention and abstinence rates and (2) changes in concomitant drug use and somatic and mental health. Methods: A prevalence sample of $n=2,694$ maintenance patients, recruited from a nationally representative sample of $n=223$ substitution doctors, was evaluated in a 6-year prospectivelongitudinal naturalistic study. At 72 months, $n=1,624$ patients were assessed for outcome; 1,147 had full outcome data, 346 primary outcome data and 131 had died; 660 individuals were lost to follow-up. Results: The 6-year retention rate was $76.6 \%$; the average mortality rate was $1.1 \%$. During follow-up, $9.4 \%$ of patients became "abstinent" and $1.9 \%$ were referred for drug-free addiction treatment. Concomitant drug use decreased and somatic health status and social parameters improved. Conclusions: The study provides fur-
\end{abstract}

\section{KARGER}

๑ 2017 S. Karger AG, Basel

E-Mail karger@karger.com

www.karger.com/ear ther evidence for the efficacy and safety of maintenance treatment with opioid agonists. In the long term, the number of opioid-free patients is low and most patients are more or less continuously under opioid maintenance therapy. Further implications are discussed.

(c) 2017 S. Karger AG, Basel

\section{Introduction}

Opioid use disorders are defined by a problematic pattern of substance use that leads to clinically significant impairment in different areas. ICD-10 [1] and DSM-IV [2] define opioid dependence as a chronic medical disorder characterised by a cluster of somatic, psychological and behavioural symptoms. Both classification systems follow a categorical approach and list 11 symptoms for opioid use disorders. The recently published DSM-5 [3] uses a dimensional approach and also lists 11 symptoms for substance use disorders, including opioid use. The presence of 6 or more symptoms indicates a severe use disorder; 4-5 are moderate and 2-3 are mild ones.

Opioid dependence is a chronic relapsing disorder with a significant mortality rate [4-6] and a high rate of psychiatric and somatic comorbidities. The non-medical 
use of opioids, including heroin, represents a significant public health problem. Epidemiological studies indicate that the worldwide prevalence of opioid use disorders is about $0.4 \%$ in individuals aged $15-64$ and that there are 15.5 million opioid-dependent people worldwide [7]. Epidemiological data suggest that in the European Union, prevalence rates for opioid consumption have declined in recent years [8]; however, there are still about 1.3 million individuals with problematic opioid use in the EU, with a prevalence of about $0.4 \%$. The drugs of choice have shifted somewhat from heroin towards other opioids, including methadone, buprenorphine and fentanyl [8].

In the United States, some 3.7 million individuals have used heroin at least once in their lives and 750,000$1,000,000$ individuals are currently heroin dependent $[9$, 10]. The World Health Organization (WHO) estimates that the burden of harm from opioid use is 11.2 million disability-adjusted life years (DALYs) [11] and the Global Burden of Disease study estimates that the burden of harm from opioid dependence is 9.2 million DALYs [5, 12]. In addition, the United States in particular has an epidemic of opioid prescription drug use and has recorded multiple deaths associated with an overdose of opioid pain killers, including many accidental poisonings in children $[13,14]$.

Opioid maintenance treatment is a well-established first-line approach for opioid dependence. Methadone, buprenorphine or the combination of buprenorphine and naloxone is frequently used [15-19]. Methadone and buprenorphine have proven efficacy and are widely used in opioid dependence [review by 16, 20-24]. However, only a few long-term studies have been performed, mostly in patients in methadone maintenance $[25,26]$. In addition, patients in studies of opioid agonists are hardly representative of the majority of opioid users and individuals with concurrent disorders are usually excluded [27]. Previously, we reported the 1-year outcome of a large sample of opioid-dependent patients treated in various naturalistic outpatient settings in Germany provided by specialized substitution centres and office-based doctors [28]. Here, we report the long-term outcome (6 years) of these patients.

This prospective, longitudinal 6-year observational naturalistic study describes the course and outcome of patients in routine maintenance treatment in Germany. A random sample of patients was recruited at a nationally representative sample of maintenance settings. The study addressed the following questions: (1) what is the 6-year outcome in terms of retention, mortality and abstinence (or transfer to abstinence treatment)? (2) What is the 6-year outcome in terms of the reduction of concomitant drug use and improvement of patients' somatic and mental health status?

\section{Methods}

Design

Details of the study and the 1-year outcome have been reported in detail elsewhere $[19,24,28,29]$. In brief, this was an observational 6-year prospective longitudinal study in an unselected prevalence sample of patients in maintenance treatment at a nationally representative sample of all substitution doctors in Germany [24, 28 . The study included a comprehensive baseline and a 12- and 72-month follow-up. Assessments consisted of a self-report patient questionnaire, urine tests and a comprehensive clinical interview and treatment documentation by the treating doctor.

\section{Participants}

Initially, a random sample of 379 doctors from a nationwide register of over 2,500 licensed and registered doctors qualified to conduct opioid maintenance therapy was invited to participate in the study; 223 agreed to participate (response rate: $58.8 \%$ ). The sample was stratified to include a sufficiently high number of different settings and their patients. Settings ranged from officebased, mostly primary care settings, to office-based doctors to large-scale, specialized substitution centres. For further details, see Wittchen et al. [24, 28].

At baseline, a total of $n=2,694$ patients were enrolled from these 223 settings. The total baseline response rate of all eligible patients was $71.7 \%$. The enrolment and all assessment procedures were checked by external monitors, for example, by comparing the initial list of all patient characteristics with those on the patient assessment forms.

All patients aged at least 16 years with current opioid dependence who were currently in agonist maintenance therapy with either buprenorphine or methadone were eligible for the study. Exclusion criteria included acute medical emergencies $(n=11 \mathrm{ex}$ cluded), cognitive impairments severe enough to compromise meaningful completion of the self-report forms $(n=21)$, unwillingness to comply with study procedures, including the mandatory urine tests $(n=17)$, and not being fluent in German (exact $n$ is unknown, but only very few participants were excluded for this reason). Each patient gave written informed consent and the study protocol was approved by the Ethics Committee of the Medical Faculty, Technische Universität Dresden, Germany.

\section{Follow-Up, Reasons for Non-Participation and Drop Out}

Figure 1 describes the flow of the original $n=2,694$ patients from baseline through the follow-up periods and the respective intermediate assessments. A total of $n=45$ doctors who had been treating $n=471$ patients were not available at the second follow-up (T3; 3 doctors had died, 14 settings had been resolved and 28 doctors had discontinued their study participation for various reasons); however, we found 61 of the patients from these 45 doctors in other medical practices. Thus, information was documented for $n=2,284$ patients (conditional response rate: $71.1 \%$ ). Of these 2,284 patients, $n=1,624$ were assessed for outcome at the final comprehensive 72 -month follow-up inves- 


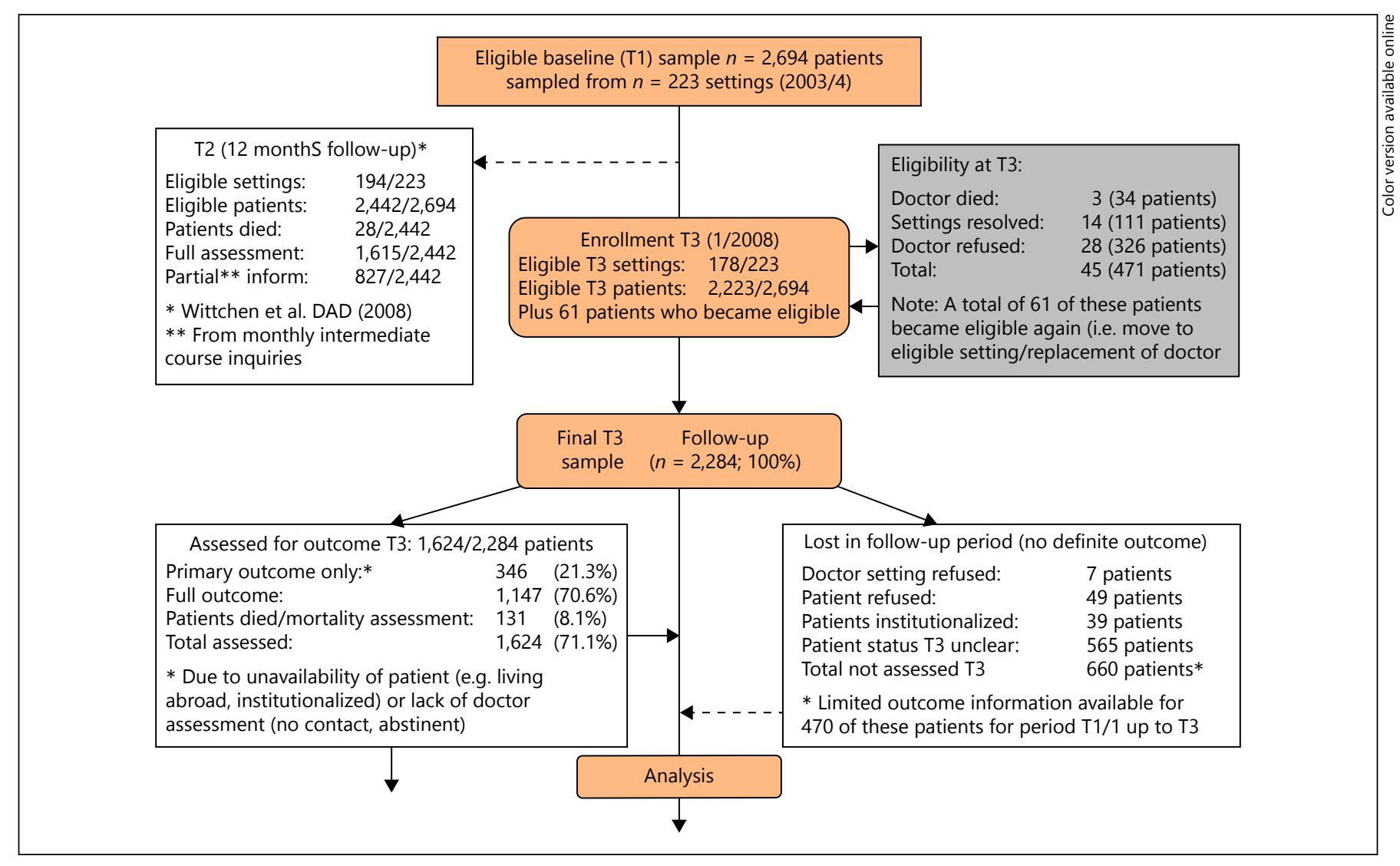

Fig. 1. Flow diagram of patients.

tigation (T3); $n=660$ patients were lost to follow-up between T2 (12-month follow-up) and T3, as follows: $n=80$ patients discontinued treatment within the observation period because of changes of residence, imprisonment for longer periods of time or changes in maintenance treatment (change in doctor or type of substitution drug); the treating doctor decided to discontinue maintenance therapy for an additional $n=6$ patients for disciplinary reasons, mostly because of serious concomitant drug use; and $n=574$ of the patients were not assessed at some point during the 72-month period for various other reasons. In total, $n=1,070$ patients were lost to follow-up during the 72 -month observation period.

Among the patients assessed for outcome at the final follow-up $(n=1,624), 1,147$ patients had full outcome information, 346 had primary outcome information only and 131 patients had died (one additional patient was treated with codeine, for details on mortality see [19]). Among the $n=1,493$ patients alive and assessed for outcome at T3, $n=1,216$ were treated with methadone, $n=270$ with buprenorphine and $n=7$ with other drugs (not further dealt with in this paper). Of the 1,147 patients will full outcome information, 208 patients completed the maintenance treatment within the observation period, either because they became "clean" (i.e., successfully terminated treatment) or because they were referred to an abstinence treatment setting. Additional interviews with doctors were conducted when necessary to ascertain patients "abstinence" status (see outcome criteria).

Six-Year Outcome of Opioid Maintenance

Treatment in Heroin-Dependent Patients
The analyses reported in this paper are thus based on $n=1,493$ patients for whom follow-up and course information was obtained. Separate analyses were also performed for the $n=1,147$ patients who were still in treatment at the 72-month follow-up assessment (i.e., excluding those who were not retained in treatment, had died or became abstinent) for whom complete baseline and follow-up documentation were available.

\section{Assessment}

The patient questionnaire consisted largely of various components of established instruments such as item groups of the European Addiction Severity Index (EuropASI) [30] and modules of the substance use questions of the WHO Composite International Diagnostic Interview (CIDI) [31]. The patient questionnaire covered the following domains: (i) basic biosocial and socio-demographic information, (ii) social and legal life developmental history and status ratings, (iii) past and current drug use and illness history module (CIDI), (iv) mental health and substance use diagnostic status (DSM-IV substance use and other mental disorders by CIDI), (v) self-reported physical disorders (e.g., hepatitis C, HIV), (vi) past and current social role impairments, disabilities and problems specific to drug use, (vii) past and current treatment history, (viii) met and unmet subjective needs, (ix) current and past experiences with treatments, (x) quality of life [32] and (xi) risk behaviours (e.g., needle sharing, unprotected sexual behaviour). 
Clinical Interview and Assessment

The doctor evaluated each patient with a standardized interview and appraisal that covered (i) current and past maintenance treatments along with documentation of onset and interruption of all lifetime treatment episodes (e.g., dosage, dosing status), (ii) licit and illicit substance use behaviours and substance use, including severity ratings, (iii) past and current physical and mental disorders, the severity of which was rated with the Clinical Global Impression scale [33], and current and past treatments (e.g., mental and selected somatic disorders, e.g., HCV and HIV status), (iv) multidimensional evaluation of social and psychological functioning, (v) past and current maintenance-related interventions, (vi) compliance and problems of management, (vii) individual treatment targets, (viii) an abbreviated EuropASI rating to assess treatment needs and (ix) ratings of health risk behaviours (needle sharing, etc.). No formal training was provided for the EuropASI administration.

\section{Urine Drug Screens}

All patients underwent standardized urine drug screenings, supervised by a nurse, at baseline and all follow-ups. Drug screening tools were provided by the study centre (certified Elisa test, immunochromatography, test-kit Drug screen Multi 10; von Minden $\mathrm{GmbH}$, Germany). Screening was performed for methadone, buprenorphine, other opiates, cocaine, amphetamines, methamphetamines, benzodiazepines and cannabis.

\section{Measures}

Retention was defined as the number of weeks that elapsed between study entry and the last week in opioid maintenance treatment assessed at 3-month intervals. Retention rates were calculated for the total sample without those who had become abstinent. Mortality was defined as any death occurring during the follow-up period and after study entry, irrespective of the cause of death. Abstinence/abstinence treatment was defined as successful discontinuation of maintenance treatment by the doctor, either because the patient was considered to be clean (no positive opiate urine screens for 4 weeks) or because of change to abstinence treatments. Information about abstinence was based on the treating doctor's rating in the follow-up interviews and a negative urine test, without consideration of whether treatment was continued or discontinued. Additionally, separate telephone interviews were conducted with these doctors 2-4 months later to confirm whether patients were still abstinent. Only patients who were confirmed to be still abstinent at this 2 nd interview were counted as abstinent. Concomitant drug use was defined as a positive urine sample on the day of the personal examination (baseline and follow-ups). Any positive screening for non-prescribed opiates (methadone, buprenorphine, others such as codeine), cannabis, cocaine, methamphetamine, amphetamine, benzodiazepine and hallucinogens was counted. The presence of methadone in buprenorphine patients was counted as concomitant drug use and vice versa. Somatic health and mental health were defined as the presence of clinicianrated ICD-10 diagnoses of 9 explicitly described groups of somatic disorders (e.g., cardiovascular conditions, liver diseases) with an open entry question, and 12 groups of mental disorders. Doctors were encouraged to code all applicable diagnoses definitely present during the past 12 months. In addition, the Brief Symptom Inventory (BSI) total score was used to evaluate changes between baseline and follow-up in the past week self-reported psychopathology.

\section{Statistical Procedures}

We used multiple imputation with chained equations and applied the procedure ICE in Stata, version 12.1. Twenty imputed data sets were created with a total of 324 imputed variables (239 from T3 and 85 auxiliary variables from prior assessments) related to substitution, treatment, morbidity and socio-demographic status. The variables were sorted in ascending order by the fraction of missing data and filled by regressing on the respective chosen predictors. This procedure was cycled 10 times over all variables to achieve convergence.

For the 1,147 patients who had full outcome data at T3, data imputation was first based on 13 core predictors with few missing values (education, age, professional and educational status, substitution status, number of substitution drugs, duration of maintenance treatment, ASI severity index, BSI severity index; if necessary, these were in turn imputed by using the remaining variables and pre-measurements of the respective variables as predictors). Then we added pre-measurements of the respective variable and other measures from either the doctor or the patient taken from similar domains (e.g., mental problems and physical diseases used to predict mental problems) that predicted the respective variable. Among the included variables, a backward selection was conducted if necessary (too few cases, empty cells, collinearity) to obtain more stable predictions. For each imputed variable, the regression model was chosen in accordance with the distribution of that variable (linear, logistic, cumulative logistic, negative binomial regression).

For 346 patients, information only on the primary outcome variables was available. Consequently, multiple imputation by chained equations could not be performed because it would have resulted in the missing values being replaced by the overall mean values. The selected variables of the doctor questionnaire and patient self-report as reported above were imputed by a regression approach that included the following predictor variables: age, gender, professional status, family status, type of substitution at T0 and T3, years of opiate use, years since first maintenance treatment and number of months of current maintenance treatment. Additionally, mental and somatic diseases at T3 were also predicted by the disease status at T0.

The variables observed at $\mathrm{T} 0$ predicted the $\mathrm{T} 3$ variables, including missing values, by logistic regression models for categorical variables and by linear regression models for dimensional variables. The few missing values in the T0 predictor variables were imputed by their mean values.

\section{Results}

Socio-Demographic and Selected Clinical

Characteristics of the Study Sample

Table 1 presents the baseline demographics and selected structured clinical interview information for the total sample.

Full outcome at T3 was reported for 1,147 patients and primary outcome only for 346 patients. 
Table 1. Sociodemographic and clinical characteristics of patients

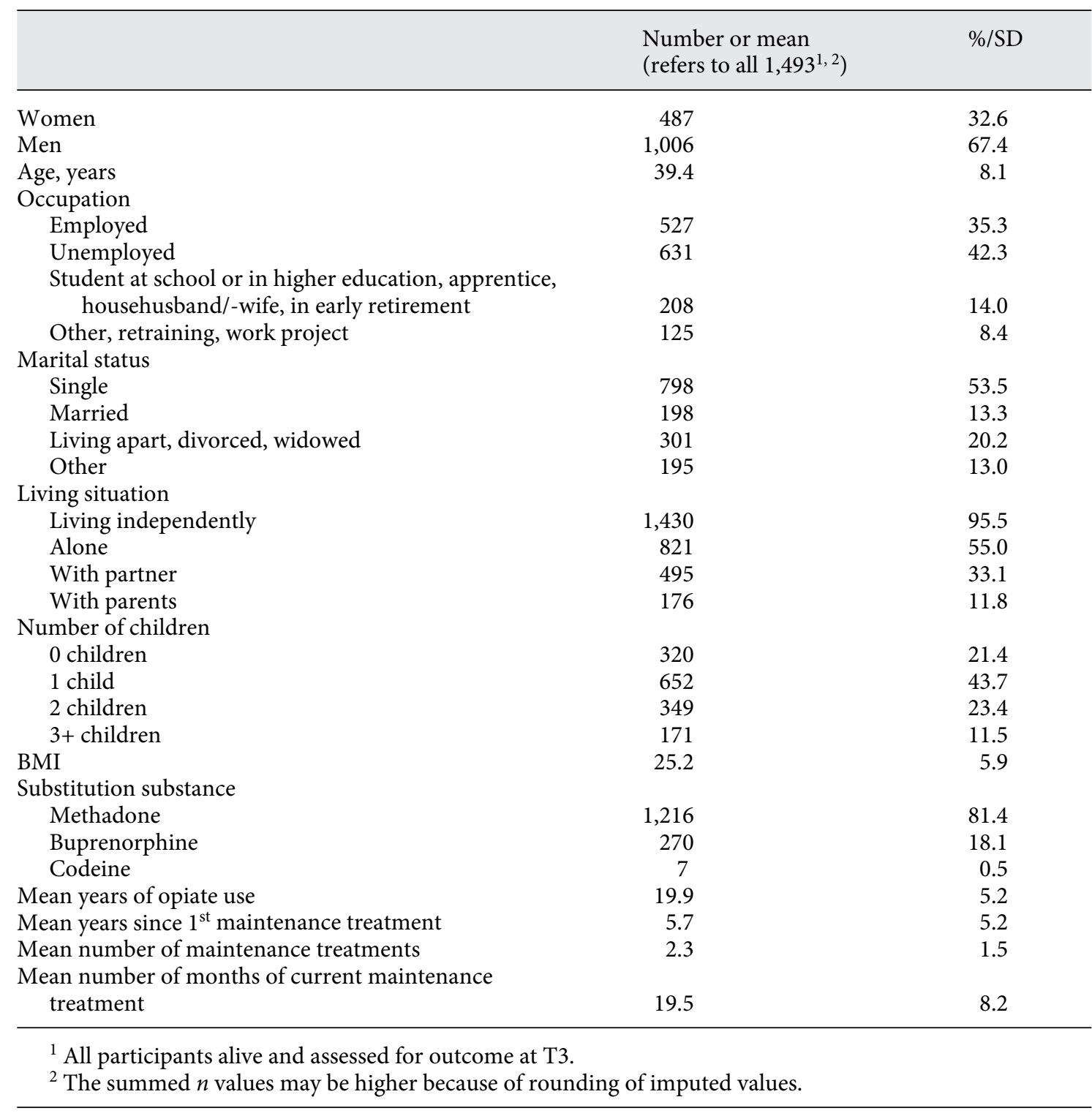

Discontinuation, Death and Abstinence in the Total Sample and by Provider Setting

Overall, at the end of the 6-year observation period, 1,144 out of $1,493(76.6 \%)$ patients with primary or full outcome data were retained in treatment and 349 out of $11,493(23.4 \%)$ were no longer in maintenance treatment. Among these 349 patients, 140 of 1,493 (9.4\%) were opiate free (abstinent), 28 out of 1,493 (1.9\%) were currently in inpatient treatment, 15 out of 1,493 (1.0\%) in prison and 124 out of $1,493(8.3 \%)$ had an unclear outcome.

Six-Year Outcome of Opioid Maintenance Treatment in Heroin-Dependent Patients
747 out of $1,493(50.0 \%)$ had a stable outcome in maintenance treatment, 207 out of 1,493 (13.9\%) an unstable outcome (on and off, change of treatment setting).

\section{Changes in Concomitant Drug Use, Somatic and}

\section{Mental Health}

The Europ-ASI and BSI scores (Table 2) indicated a significant improvement of all domains assessed over time. The data on concomitant drug use indicated a significant improvement of drug intake (opioid use) from baseline (T0) to the 72-month follow-up (T3, see Table 2). The urine 
Table 2. Comparison of BSI scores and concomitant drug use at T0 (baseline) and T3 (60-month follow-up)

\begin{tabular}{|c|c|c|c|c|c|c|c|c|}
\hline & \multicolumn{2}{|l|}{ T0 } & \multicolumn{2}{|l|}{$\mathrm{T} 3$} & \multicolumn{4}{|l|}{ T3 vs. T0 } \\
\hline & $\begin{array}{l}\text { number or } \\
\text { mean }\end{array}$ & $\%$ or $\mathrm{SD}$ & $\begin{array}{l}\text { number or } \\
\text { mean }\end{array}$ & $\%$ or SD & OR or MD & $95 \% \mathrm{CI}$ & & $p$ value \\
\hline \multicolumn{9}{|l|}{$B S I$} \\
\hline GSI & 0.71 & 0.54 & 0.61 & 0.51 & -0.10 & -0.13 & -0.07 & 0.000 \\
\hline \multicolumn{9}{|l|}{ Concomitant drug use } \\
\hline Cocaine & 216 & 14.5 & 505 & 33.8 & 1.55 & 1.06 & 2.28 & 0.025 \\
\hline Opiates & 252 & 16.9 & 78 & 5.2 & 1.15 & 0.56 & 2.35 & 0.699 \\
\hline Methamphetamine & 14 & 0.9 & 25 & 1.7 & - & & & \\
\hline Methadone & 221 & 14.8 & 50 & 3.3 & 0.76 & 0.21 & 2.76 & 0.681 \\
\hline Amphetamines & 125 & 8.4 & 9 & 0.6 & 2.64 & 0.22 & 31.97 & 0.446 \\
\hline Hallucinogens & 520 & 34.8 & 973 & 65.2 & 1.66 & 1.20 & 2.29 & 0.002 \\
\hline \multicolumn{9}{|l|}{ Urine screening } \\
\hline Amphetamines & 18 & 1.23 & 25 & 1.66 & 12.93 & 1.07 & 156.63 & 0.044 \\
\hline Benzodiazepines & 313 & 20.99 & 289 & 19.40 & 6.24 & 4.33 & 8.99 & 0.000 \\
\hline Methadone & 1,140 & 76.15 & 1,220 & 81.94 & 12.55 & 9.22 & 17.07 & 0.000 \\
\hline Methamphetamine & 15 & 0.99 & 44 & 2.98 & - & & & \\
\hline Cocaine & 124 & 8.28 & 48 & 3.20 & 5.72 & 2.34 & 13.99 & 0.000 \\
\hline Opiates & 292 & 19.55 & 184 & 12.35 & 3.03 & 2.04 & 4.49 & 0.000 \\
\hline Cannabis & 645 & 43.25 & 495 & 33.16 & 4.61 & 3.49 & 6.10 & 0.000 \\
\hline Buprenorphine & & & 286 & 19.20 & - & & & \\
\hline TCA & & & 180 & 12.06 & - & & & \\
\hline
\end{tabular}

GSI, global indicator; TCA, tricyclic antidepressants; BSI, brief symptom inventory.

findings indicated that benzodiazepine use was underreported and that about $20 \%$ of patients were using benzodiazepines at T1 and T3. Alcohol and cannabis use was more frequently reported and increased over time, while urine testing suggested a decline for cannabis (and cocaine) use.

\section{Discussion}

Opioid dependence is a global problem that causes numerous social, medical and legal problems $[5,7,11,12]$. Although psychotherapy and psychosocial treatment are effective in substance use disorders [34], opioid maintenance therapy is a well-established first-line treatment and widely used for opioid dependence $[16,23]$ and is recommended by numerous treatment guidelines [10, 18, 35-37].
The findings from this large, nationally representative sample of opioid-dependent patients underline the effectiveness of opioid maintenance treatments with methadone and buprenorphine. Overall and most importantly, the data from this long-term follow-up indicate a high retention rate, with over $70 \%$ of patients still in treatment after 6 years - most in stable maintenance treatment - and a rather low rate of opioid-abstinent patients (about 9\%). While reported opioid use clearly decreased, cannabis and cocaine use increased over time, although urine testing for drugs suggested a decline. Probably many individuals used these drugs only sporadically and not continuously, as reflected by the toxicological data. Benzodiazepine use was underreported and remained stable over time; urine testing indicated that about $20 \%$ of participants were using benzodiazepines. Polydrug use remains a major con- 
cern in these patients. The relatively high number of individuals with alcohol use found in this study corresponds to similar findings in other studies (for review see [38]).

This cohort still had a significant mortality rate, which did not decline substantially over time [19], but it was lower than usually found in opioid-dependent patients. In comparison to findings from a meta-analysis by Degenhardt et al. [4], these data indicate comparably low mean crude annual mortality rates of $1.0 \%$ and 1.2 per 100 patient years, probably reflecting the beneficial effect of opioid maintenance treatment.

Somatic and psychiatric comorbidity showed some improvement, but many patients still had a significant number of other medical or psychiatric disorders over the course of the study. In general, there is substantial clinical evidence that opioid maintenance treatment has proven efficacy in reducing opioid consumption, psychosocial and medical morbidity and in increasing treatment retention rates and social functioning in opioid addicts also in the long run $[16,23]$.

In line with findings from previous clinical studies [20, 24 ], our data, which cover a longer time period than most studies, demonstrate low mortality rates of about $1 \%$ and a relatively high 6-year retention in treatment of about $70 \%$. Noteworthy is that a similar mortality rate was recently reported in a 4.5-year (mean) follow-up study of patients who had been randomized in an opioid treatment programme to receive open-label methadone or buprenorphine/naloxone [26]. Furthermore, Evans et al. [39] found a 3.2\% mortality rate in 32,322 individuals in pharmacological treatment over a 2.6-year (mean) treatment period; mortality was highest when individuals were out of treatment and during detoxification, particularly in the 2-weeks post-treatment entry. Degenhardt et al. [40] estimated the mortality reduction in opioid maintenance therapy to be $29 \%$.

Although a number of long-term studies have been performed in opioid-dependent individuals $[41,42]$ and numerous short-term clinical and experimental studies have examined the efficacy of opioid maintenance therapy [16, 23], relatively few studies have studied opioid-dependent patients in opioid maintenance treatment over long time periods. Fifteen-year follow-up data from a small group of Swedish methadone patients indicate that an opiate-free life can be achieved [43], but most studies agree that opioid-dependent patients with and without maintenance therapy have a high risk for inpatient treatments and detoxification [44]. An important 15-year follow-up of an Israeli sample $(n=613)$, published by Peles et al. [6], found that patients staying longer in treatment

Six-Year Outcome of Opioid Maintenance Treatment in Heroin-Dependent Patients had a lower mortality rate. Predictors of survival were under 40 years of age at admission, living with a partner, being hepatitis B sera-negative, no benzodiazepine abuse, being referred from hospital to maintenance treatment and not leaving treatment for hospitalization. The last 2 variables also predicted longer retention and no opioid and benzodiazepine abuse, among others. In this study, no psychiatric diagnosis was a positive predictor, while Maremmani et al. [45, 46] found the opposite result. A 4.5 years' prospective study in Macao also showed a high long-term retention of patients in opioid maintenance therapy [47]. An interesting registry-based study for methadone programs was published by Huissoud et al. [48]. The probability of remaining on treatment was $69 \%$ at 1 year and $45 \%$ at 3 years $(n=1666)$. Data from Canada indicate that long-term retention over 36 months is achieved only in $20-25 \%$ of all patients in methadone treatment, while 12-month retention figures fell from $45.9 \%$ in 2001 to $40.5 \%$ in 2005 [49].

The strengths of our study are its reliance on a large nationally representative and heterogeneous sample of maintenance treatment providers and a random sample of their patients, the 6-year duration of the observation period and the coverage of a wide range of variables describing course and outcome, including urine drug tests. In addition, relevant follow-up information was available for a majority of patients even after about 6 years. Noteworthy limitations of the study are that it was a strictly observational, naturalistic study and not a randomized control group design. Thus, causal inferences are not possible and any causal conclusions regarding the effects of different treatments and settings need to be interpreted with caution. Further limitations are as follows: (i) initially, only $59 \%$ of eligible settings participated and no information is available whether non-participating settings differed from those that participated [see 24]; (ii) patients not fluent in German were excluded from the study because of the assessment instruments, so we could not assess whether patients with a migration background have a worse outcome than those included in this study; (iii) no formal interviews with standardized psychiatric assessment instruments could be used in this study; and (iv) data on somatic comorbidity (HIV, hepatitis) were collected on the basis of clinical and interview data and no formal screening or testing was performed at T3 (6-year follow-up). Our outcome data basically rely on interviews with treating doctors and patients and additional data on psychiatric outcome could help to further elucidate predictors of outcome.

Taking into account these limitations, this study provides several basic findings: 
(1) The retention rate in routine care is relatively high, also in the long term.

(2) The annual mortality rate is lower than those usually found in untreated populations.

(3) The overall level of psychiatric and somatic symptoms decreases over time.

(4) Opioid abstinence is possible, but rather rare.

Future studies may especially address individuals with a less favourable outcome and strategies to optimize transition into drug-free living.

\section{Acknowledgement}

The authors thank Jacquie Klesing, Board-certified Editor in the Life Sciences, for editing assistance with the manuscript.

\section{Disclosure Statement}

For the past 5 years, MS has worked as a consultant or has received research grants from Lundbeck, Sanofi Aeventis, Reckitt Benckiser/Indivior, Novartis.

\section{References}

1 World Health Organization: The ICD-10 Classification of Mental and Behavioural Disorders: Clinical Descriptions and Diagnostic Guidelines. Geneva, World Health Organization, 1992.

2 American Psychiatric Association: Diagnostic and Statistical Manual of Mental Disorders, ed 4th, text revision. Washington, American Psychiatric Association, 2000.

3 American Psychiatric Association: Diagnostic and statistical manual of mental disorders, ed 5th. Arlington, American Psychiatric Association, 2013.

4 Degenhardt L, Bucello C, Mathers B, Briegleb C, Ali H, Hickman M, McLaren J: Mortality among regular or dependent users of heroin and other opioids: a systematic review and meta-analysis of cohort studies. Addiction 2011;106:32-51.

5 Degenhardt L, Whiteford HA, Ferrari AJ, Baxter AJ, Charlson FJ, Hall WD, Freedman G, Burstein R, Johns N, Engell RE, Flaxman A, Murray CJ, Vos T: Global burden of disease attributable to illicit drug use and dependence: findings from the global burden of disease study 2010. Lancet 2013;382:1564-1574.

6 Peles E, Schreiber S, Adelson M: 15-year survival and retention of patients in a general hospital-affiliated methadone maintenance treatment (MMT) center in Israel. Drug Alcohol Depend 2010;107:141-148.

7 United Nations Office on Drugs and Crime: 2006 world drug report. Vienna, UNODC, 2006.

8 EMCDDA: European drug report 2014. Lisbon, EMCDDA, 2014.

9 Kessler RC, Avenevoli S, Costello EJ, Georgiades K, Green JG, Gruber MJ, He JP, Koretz D, McLaughlin KA, Petukhova M, Sampson NA, Zaslavsky AM, Merikangas KR: Prevalence, persistence, and sociodemographic correlates of DSM-IV disorders in the national comorbidity survey replication adolescent supplement. Arch Gen Psychiatry 2012;69:372-380.

10 Kleber HD, Weiss RD, Anton RF Jr, George TP, Greenfield SF, Kosten TR, O'Brien CP, Rounsaville BJ, Strain EC, Ziedonis DM, Hennessy G, Connery HS, McIntyre JS, Charles
SC, Anzia DJ, Cook IA, Finnerty MT, Johnson BR, Nininger JE, Summergrad P, Woods SM, Yager J, Pyles R, Cross CD, Peele R, Shemo JP, Lurie L, Walker RD, Barnovitz MA, Gray SH, Saxena S, Tonnu T, Kunkle R, Albert AB, Fochtmann LJ, Hart C, Regier D: Treatment of patients with substance use disorders, second edition. American psychiatric association. Am J Psychiatry 2007;164(4 suppl):5-123.

11 World Health Organization: The World Health Report 2004. Geneva, World Health Organization, 2004.

12 Degenhardt L, Charlson F, Mathers B, Hall WD, Flaxman AD, Johns N, Vos T: The global epidemiology and burden of opioid dependence: results from the global burden of disease 2010 study. Addiction 2014;109:13201333.

13 Imtiaz S, Shield KD, Fischer B, Rehm J: Harms of prescription opioid use in the United States. Subst Abuse Treat Prev Policy 2014;9:43.

14 Lavonas EJ, Banner W, Bradt P, Bucher-Bartelson B, Brown KR, Rajan P, Murrelle L, Dart RC, Green JL: Root causes, clinical effects, and outcomes of unintentional exposures to buprenorphine by young children. J Pediatr 2013;163:1377-1383.e1-e3.

15 Mammen K, Bell J: The clinical efficacy and abuse potential of combination buprenorphine-naloxone in the treatment of opioid dependence. Expert Opin Pharmacother 2009; 10:2537-2544.

16 Mattick RP, Breen C, Kimber J, Davoli M: Buprenorphine maintenance versus placebo or methadone maintenance for opioid dependence. Cochrane Database Syst Rev 2014; 2:CD002207.

17 Soyka M: New developments in the management of opioid dependence: focus on sublingual buprenorphine-naloxone. Subst Abuse Rehabil 2015;6:1-14.

18 Soyka M, Kranzler HR, van den Brink W, Krystal J, Moller HJ, Kasper S: The world federation of societies of biological psychiatry (WFSBP) guidelines for the biological treatment of substance use and related disorders. Part 2: Opioid dependence. World J Biol Psychiatry 2011;12:160-187.
19 Soyka M, Trader A, Klotsche J, Backmund M, Buhringer G, Rehm J, Wittchen HU: Six-year mortality rates of patients in methadone and buprenorphine maintenance therapy: results from a nationally representative cohort study. J Clin Psychopharmacol 2011;31:678680.

20 Connock M, Juarez-Garcia A, Jowett S, Frew E, Liu Z, Taylor RJ, Fry-Smith A, Day E, Lintzeris N, Roberts T, Burls A, Taylor RS: Methadone and buprenorphine for the management of opioid dependence: a systematic review and economic evaluation. Health Technol Assess 2007;11:1-171, iii-iv.

21 Gossop M, Marsden J, Stewart D, Treacy S: Outcomes after methadone maintenance and methadone reduction treatments: two-year follow-up results from the national treatment outcome research study. Drug Alcohol Depend 2001;62:255-264.

22 Kakko J, Svanborg KD, Kreek MJ, Heilig M: 1 -year retention and social function after buprenorphine-assisted relapse prevention treatment for heroin dependence in Sweden: a randomised, placebo-controlled trial. Lancet 2003;361:662-668.

23 Mattick RP, Breen C, Kimber J, Davoli M: Methadone maintenance therapy versus no opioid replacement therapy for opioid dependence. Cochrane Database Syst Rev 2009; 3:CD002209.

24 Wittchen HU, Apelt SM, Buhringer G, Gastpar M, Backmund M, Golz J, Kraus MR, Tretter F, Klotsche J, Siegert J, Pittrow D, Soyka M: Buprenorphine and methadone in the treatment of opioid dependence: methods and design of the cobra study. Int J Methods Psychiatr Res 2005;14:14-28.

25 Hser YI, Evans E, Grella C, Ling W, Anglin D: Long-term course of opioid addiction. Harv Rev Psychiatry 2015;23:76-89.

26 Hser YI, Evans E, Huang D, Weiss R, Saxon A, Carroll KM, Woody G, Liu D, Wakim P, Matthews AG, Hatch-Maillette M, Jelstrom E, Wiest K, McLaughlin P, Ling W: Long-term outcomes after randomization to buprenorphine/naloxone versus methadone in a multisite trial. Addiction 2016;111:695-705. 
27 Dennis BB, Roshanov PS, Naji L, Bawor M, Paul J, Plater C, Pare G, Worster A, Varenbut M, Daiter J, Marsh DC, Desai D, Samaan Z, Thabane L: Opioid substitution and antagonist therapy trials exclude the common addiction patient: a systematic review and analysis of eligibility criteria. Trials 2015;16:475.

28 Wittchen HU, Apelt SM, Soyka M, Gastpar M, Backmund M, Golz J, Kraus MR, Tretter F, Schafer M, Siegert J, Scherbaum N, Rehm J, Buhringer G: Feasibility and outcome of substitution treatment of heroin-dependent patients in specialized substitution centers and primary care facilities in germany: a naturalistic study in 2694 patients. Drug Alcohol Depend 2008;95:245-257.

29 Wittchen HU, Boehringer G, Rehm JT, Soyka M, Träder A, Mark K, Trautmann S: [The course and outcome after 6 years of substitution patients under current conditions of substitution care in Germany]. Suchtmed 2011; 13:232-246.

30 Gsellhofer B, Kufner H, Vogt M, Weller D: European addiction severity index - Europasi. Manual for Training and Execution. Stuttgart, Schneider Verlag, 1999.

31 Wittchen HU, Lachner G, Wunderlich U, Pfister H: Test-retest reliability of the computerized DSM-IV version of the MunichComposite International Diagnostic Interview (M-CIDI). Soc Psychiatry Psychiatr Epidemiol 1998;33:568-578.

32 Greiner W, Weijnen T, Nieuwenhuizen $M$, Oppe S, Badia X, Busschbach J, Buxton M, Dolan P, Kind P, Krabbe P, Ohinmaa A, Parkin $\mathrm{D}$, Roset $\mathrm{M}$, Sintonen $\mathrm{H}$, Tsuchiya A, de Charro F: A single European currency for EQ5D health states. Results from a six-country study. Eur J Health Econ 2003;4:222-231.

33 Guy W: Clinical global impressions; in National Institute of Mental Health (ed): Ecdeu assessment manual for psychopharmacology, ed 1st. Rockville, National Institute of Mental Health, 1976, pp 21-27.

34 Dutra L, Stathopoulou G, Basden SL, Leyro TM, Powers MB, Otto MW: A meta-analytic review of psychosocial interventions for substance use disorders. Am J Psychiatry 2008; 165:179-187.

35 Lingford-Hughes AR, Welch S, Peters L, Nutt DJ: Bap updated guidelines: evidence-based guidelines for the pharmacological management of substance abuse, harmful use, addiction and comorbidity: recommendations from BAP. J Psychopharmacol 2012;26:899_ 952.

36 New South Wales Department of Health: Opioid Treatment Program: Clinical Guidelines for Methadone and Buprenorphine Treatment. Sydney, NSW Government, 2011.

37 World Health Organization: Guidelines for the Psychosocially Assisted Pharmacological Treatment of Opioid Dependence. Geneva, World Health Organization, 2009.

38 Soyka M: Alcohol use disorders in opioid maintenance therapy: prevalence, clinical correlates and treatment. Eur Addict Res 2015;21:78-87.

39 Evans E, Li L, Min J, Huang D, Urada D, Liu L, Hser YI, Nosyk B: Mortality among individuals accessing pharmacological treatment for opioid dependence in california, 2006-10. Addiction 2015;110:996-1005.

40 Degenhardt L, Randall D, Hall W, Law M, Butler T, Burns L: Mortality among clients of a state-wide opioid pharmacotherapy program over 20 years: risk factors and lives saved. Drug Alcohol Depend 2009;105:915.

41 Bjornaas MA, Bekken AS, Ojlert A, Haldorsen T, Jacobsen D, Rostrup M, Ekeberg O: A 20-year prospective study of mortality and causes of death among hospitalized opioid addicts in Oslo. BMC Psychiatry 2008;8:8.
42 Hser YI, Anglin D, Powers K: A 24-year follow-up of California narcotics addicts. Arch Gen Psychiatry 1993;50:577-584.

43 Hiltunen AJ, Eklund C, Borg S: The first 38 methadone maintenance treatment patients in Stockholm: 15-year follow-up with a main focus on detoxification from methadone. Nord J Psychiatry 2011;65:106-111.

44 Nosyk B, Li L, Evans E, Urada D, Huang D, Wood E, Rawson R, Hser YI: Utilization and outcomes of detoxification and maintenance treatment for opioid dependence in publiclyfunded facilities in California, USA: 1991-2012. Drug Alcohol Depend 2014;143:149-157.

45 Maremmani AG, Rovai L, Bacciardi S, Rugani F, Pacini M, Pani PP, Dell'Osso L, Akiskal H, Maremmani I: The long-term outcomes of heroin dependent-treatment-resistant patients with bipolar 1 comorbidity after admission to enhanced methadone maintenance. J Affect Disord 2013;151:582-589.

46 Maremmani I, Pacini M, Lubrano S, Perugi G, Tagliamonte A, Pani PP, Gerra G, Shinderman M: Long-term outcomes of treatmentresistant heroin addicts with and without DSM-IV axis I psychiatric comorbidity (dual diagnosis). Eur Addict Res 2008;14:134-142.

47 Adelson M, Wilson HW, Celeste VY, Linzy S, Kreek MJ, Peles E: Methadone maintenance treatment experience in Macao - prospective follow-up for initial 4.5 years. J Psychoactive Drugs 2013;45:313-321.

48 Huissoud T, Rousson V, Dubois-Arber F: Methadone treatments in a Swiss region, 2001-2008: a registry-based analysis. BMC Psychiatry 2012;12:238.

49 Nosyk B, Marsh DC, Sun H, Schechter MT, Anis AH: Trends in methadone maintenance treatment participation, retention, and compliance to dosing guidelines in British Columbia, canada: 1996-2006. J Subst Abuse Treat 2010;39:22-31. 